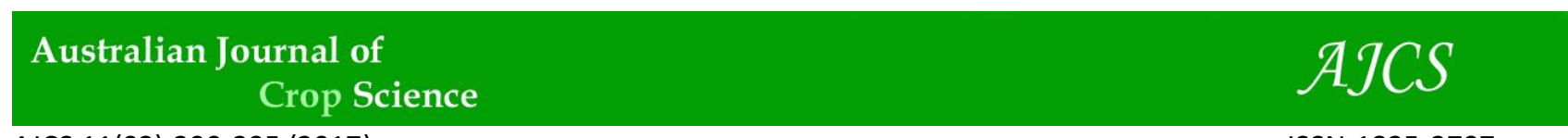

AJCS 11(03):290-295 (2017)

ISSN:1835-2707

doi: 10.21475/ajcs.17.11.03.p7684

\title{
Comparison of root xylem structure and hydraulic conductivity of triticale (X Triticosecale Wittmack) genotypes under salt stress
}

\section{Ehsan Bijanzadeh*}

\author{
College of Agriculture and Natural Resources of Darab, Shiraz University, Iran
}

*Corresponding author: bijanzd@shirazu.ac.ir

\begin{abstract}
To compare the root xylem and hydraulic conductivity of triticale genotypes (Sanabad, Juanillo, and ET-84-5) an experiment was carried out at two concentrations of $\mathrm{NaCl}(0$ and $100 \mathrm{mM})$, hydroponically. When seedlings had a root length of $25-30 \mathrm{~mm}$, they were transferred to a modified half-strength Hoagland nutrient solution in growth chamber. Then, xylem anatomy, root surface area, hydraulic conductivity, growth rate, and water loss in 14 to 18 days old plants were measured. The xylem anatomy was considered on free-hand cross-sections that were made from 5-10 mm root tips. Root surface area was determined by measuring the length and the radius of the main axis of seminal, adventitious and lateral roots of the 18 days old plants. Under salt, the length of seminal and adventitious roots decreased significantly and ranged from $53 \pm 4$ to $29 \pm 5 \mathrm{~mm}$ and $11 \pm 1$ to $9 \pm 2 \mathrm{~mm}$, respectively. In all genotypes, salinity more negatively affected the diameter of central and peripheral metaxylem vessels compared to the number of vessels. The stellar cells in all genotypes were less lignified in adventitious roots and the mature xylem vessels of seminal roots of ET-84-5 and Sanabad had the most lignified walls. In all genotypes, the central metaxylem of seminal roots was less lignified compared to the peripheral metaxylem. Under salinity, the casparian bands could be detected more in the seminal roots as U-shape especially in ET84-5 and Sanabad. The surface area of seminal root differed among the genotypes from $1.67 \times 10^{-3} \mathrm{~m}^{2}$ in Juanillo to $1.04 \times 10^{-3} \mathrm{~m}^{2}$ in Sanabad under salt stress. Juanillo with highest surface area and lowest thickness of lignified cell wall had the highest seminal root hydraulic conductivity $\left(5.32 \times 10^{-9} \mathrm{~m} \mathrm{~s}^{-1} \mathrm{MPa}^{-1}\right)$. It could be concluded that at the early growth stages of the triticale genotypes, the root structures of the Juanillo appeared to be more efficient for water uptake via seminal and adventitious roots and this might be attributed to less lignified cell wall of root cell.
\end{abstract}

Keywords: Casparian band, central metaxylem, root surface area, seminal roots, lignified cell wall. Abbreviation: AR_adventitious roots; SR_seminal roots; CMX_central metaxylem; PMX_peripheral metaxylem: CB_casparian bands.

\section{Introduction}

After a decade of genetic manipulation and breeding, triticale (X Triticosecale Wittmack) stands out as a crop of high grain yield potential which generally surpasses that of wheat. Its high productivity is most likely derived from high rates of carbon assimilation linked to stomatal physiology and probably low respiration rate. Being a derivative of rye, triticale has always been assumed to be relatively resistant to abiotic stresses such as salinity (Blum, 2014). Saline soils occupy more than $6 \%$ of the world's land area. It is estimated that over 800 million hectares of land in the world are affected by both salinity and sodicity (Munns, 2005). Because of a rapid increase in demand for food production in inevitable due to the world population rising; therefore, there is a need to have salt-tolerant crop genotypes in saline lands for proper cultivation to meet this increasing demand. One way to achieving this goal may be done using a better understanding of the root anatomy and water uptake of salt tolerance of different genotypes so that the traits leading to salt tolerance can be introduced in the new genotypes (Wieland et al., 2014).

Many studies have revealed that high salinity levels reduce the size of the vein segments and number of small veins $(\mathrm{Hu}$ et al., 2005), stomata number (Hwang and Chen 1995; Cavusoglu et al., 2007), and leaf thickness (Cavusoglu et al.,
2008; Bijanzadeh and Kazemeini, 2014). Other structural changes such as inhibition of differentiation, diameter and number of xylem vessels also occur in salt stressed plants (Ola et al., 2012). Karray-Bouraoui et al. (2001) declared that common salinity tolerance of triticale at least as high as in wheat and close to barley under saline hydroponics culture. Root anatomy plays a major role in root hydraulic, influencing axial conductance and the distribution of water uptake along the root with a more localized role for aquaporins (Bramely et al., 2009). These membrane integral proteins form water-conducting channels, responsible for the variable hydraulic conductivity of root systems (Javot and Maurel, 2002). In addition to stomata, the water status of the shoot will be largely determined by root hydraulic conductivity (Knipfer and Steudle, 2008). Root hydraulic properties could be changed with the magnitude of water flow induced across roots (Passioura and Munns, 1984; Mureal et al., 2010). The hydraulic conductivity of a root is a complex parameter because of the complicated structure of the osmotic barrier made up of exodermis, cortex and endodermis (Kramer and Boyer, 1995).

On the other hand, excessive soil salinity is an important external factor reducing root and shoot growth particularly in field crops. Although good management practices may give 
partial amelioration of damage by saline soil, an inherent tolerance of crop cultivars to salinity remains highly desirable (Flowers, 2004; Blum 2014). Achieving this will require a better understanding of plant growth responses to salinity and of how some plant species and varieties achieve greater saltresistance than others. Inhibitory effects of salinity on plant growth can be attributed to decreased availability of water imposed by an osmotic stress or to toxic effect of excessive $\mathrm{Na}^{+}$or $\mathrm{Cl}^{-}$ions (Veselov et al., 2009).

Considering the importance of triticale, where is mainly growing in saline conditions (Blum, 2005), better understanding of the relationship between root anatomy and hydraulic conductivity for triticale genotypes would be of great priority. With respect to differing salinity tolerance in triticale genotypes (Munns, 2005; Rakeih et al., 2008; Salehi and Arzani, 2011), the root anatomy and water movement in different genotypes at early growth stages need to be explored more in detail and are still poorly understood. The objectives of the present study were comparison of root surface area, root to shoot ratio, seminal and adventitious root dimensions and their hydraulic conductivity, at the third leaf stage of three triticale genotypes, under salt stress condition.

\section{Results and Discussion}

\section{Anatomy and xylem dimensions of triticale roots}

The seminal roots were the first major roots appeared, after radicle formation and adventitious roots appeared when seedlings were 10-14 days old, differing in anatomy from seminal roots (Fig.1). The thicker adventitious roots had more cortical cell layers and contained more central metaxylem vessels of larger diameter than the seminal roots (Fig. 2). As plants were 18 days old (the developmental stage at which they were analyzed), there were three to six seminal roots and two to three stem-borne adventitious roots in each plant. Under normal conditions $(0 \mathrm{mM} \mathrm{NaCl})$, the mean length of seminal and adventitious roots ranged from $84 \pm 4$ to $62 \pm 1 \mathrm{~mm}$ and $41 \pm 3$ to $22 \pm 2$ at 18 days old plants, respectively. Also, under salt stress conditions $(100 \mathrm{mM}$ $\mathrm{NaCl}$ ), the length of seminal and adventitious roots of triticale genotypes decreased significantly and ranged from $53 \pm 4$ to $29 \pm 5 \mathrm{~mm}$ and $11 \pm 1$ to $9 \pm 2$, respectively (data not shown).

In triticale genotypes, in both normal and salt stress condition, seminal roots had a mean diameter of $721 \pm 83 \mu \mathrm{m}$, between four and six cortical cell layers, and typically one large central metaxylem, and $5 \pm 1$ to $8 \pm 2$ smaller and circularly arranged peripheral metaxylem vessels (Table 1 and Fig. 2-A,B,E,F,I,J). In similar study on barley, Knipfer and Fricke (2010b) declared that the peripheral metaxylem vessels were early metaxylem, being fully functional during the early stages of development of a root segment, while the central vessel was late metaxylem, being the last of the xylem elements to become fully functional. The adventitious roots were much thicker compared to seminal roots, having 6 to 8 cortical cell layers, with $2 \pm 1$ to $3 \pm 1$ central metaxylem and $7 \pm 2$ to $10 \pm 2$ peripheral metaxylem vessels (Table 1 and Fig. 1-C,D,G,H,K,L). Zhao et al. (2004) also found that in wheat, the diameter of the adventitious root was 1.7 to 2.5 fold thicker than the seminal root at the three to six leaf stage plants.

When plants exposed to $100 \mathrm{mM} \mathrm{NaCl}$, the mean diameter of the central and peripheral metaxylem vessels of seminal roots were $27 \pm 3$ and $13 \pm 4 \mu \mathrm{m}$, respectively (Table 1 and Fig. 2). Steudle (2000) showed that the diameter of the central metaxylem of the seminal roots varied from 52 to $200 \mu \mathrm{m}$ at the early growth stages of wheat and barley. In all genotypes, the diameter of central metaxylem was more than peripheral metaxylem in seminal and adventitious roots (Fig. 2 and Table 1). Juanillo had thicker central metaxylem compared to ET-84-5 and Sanabad. Overall, in seminal and adventitious roots, the number of central metaxylem of vessels was not affected by salt stress (Fig. 2 and Table 1). Under salt stress, in the peripheral metaxylem of seminal roots, the minimum diameter of vessels was observed in ET-84-5 $(9 \pm 1 \mu \mathrm{m})$ and in adventitious roots, Sanabad and ET-84-5 with $20 \pm 2$ and $7 \pm 1$ $\mu \mathrm{m}$ had the maximum and minimum diameter of vessels, respectively. Generally, in all triticale genotypes, salinity more negatively affected the diameter of central and peripheral metaxylem vessels compared to the number of the vessels (Table 1). The stellar cells in all genotypes were less lignified in adventitious, as compared to the seminal roots and the mature xylem vessels of the seminal roots of ET-84-5 and Sanabad had the most lignified walls, compared to Juanillo in both normal and salt stress conditions (bright color, Fig. 2-C,D,G,H,K,L). Knipfer and Fricke (2010a, $2010 \mathrm{~b})$ declared that the amount of lignification area in barley xylems of seminal and adventitious roots had an important role in decreasing hydraulic conductivity and water uptake. Under normal and salt stress conditions, in all genotypes, the central metaxylem vessels of the seminal roots were less lignified compared to the peripheral metaxylems (Fig. 2 and Table 2). In fact, they could be classified as immature xylem vessels, compared to the peripheral metaxylem, which had highly lignified cell walls especially under salt stress conditions. Likewise, higher lignification thickness of cell wall of central and peripheral metaxylems vessels was observed in adventitious roots of ET-84-5 and Sanabad genotypes, when plants exposed to salt (Table 2).

Under salinity, the casparian bands could be detected more in the seminal roots as U-shape especially in ET-84-5 and Sanabad (Fig. 2-B,J), but not in the adventitious roots (Fig. 2D,L). Knipfer and Fricke (2010b) declared that casparian bands appeared during the root development prior to the formation of additional wall depositions in the endodermis. In the adventitious roots, the lowest lignification thickness of cell wall $(0.46 \mu \mathrm{m})$ was observed in the central metaxylem vessels of Juanillo compared to ET-84-5 and Sanabad, under salt stress (Table 2 and Fig. 2). Peterson et al. (1993) reported that in young maize roots, the formation of a casparian band in the exodermis did not affect hydraulic conductivity. Overall, in all cultivars, under salt stress, central and peripheral metaxylem vessels had more lignified cell walls compared to non-stress conditions (Table 2). Similarly, Steudle (2000) found that suberization of roots increases with age and during stress (drought, high salinity, nutrient deprivation, etc.).

\section{Root surface area and hydraulic conductivity}

As shown in Table 3, at 18-day-old plants, ET-84-5 genotype had the maximum root surface area $\left(2.66 \times 10^{-3} \mathrm{~m}^{2}\right)$ of the seminal roots under normal condition, while this genotype had maximum reduction $(50 \%)$ root surface area under salt stress. The surface area of seminal root differed among the genotypes from $1.67 \times 10^{-3} \mathrm{~m}^{2}$ in Juanillo to $1.04 \times 10^{-3} \mathrm{~m}^{2}$ in Sanabad under salt stress conditions. Interestingly, Juanillo with the highest surface area (Table 3) and lowest thickness of lignified cell walls (Table 2), had the highest seminal root hydraulic conductivity $\left(5.32 \times 10^{-9} \mathrm{~m} \mathrm{~s}^{-1} \mathrm{MPa}^{-1}\right)$ whereas in ET-84-5 and Sanabad genotypes, hydraulic conductivity was as low as 3.01 and $3.08 \times 10^{-9} \mathrm{~m} \mathrm{~s}^{-1} \mathrm{MPa}^{-1}$, respectively (Table 3). Zhao et al.(2005) reported that in wheat (cv. Xiaoyan6), 
Table 1. Mean number and dimensions of mature xylem vessels at 18 days old triticale genotypes. Results are mean \pm SD.

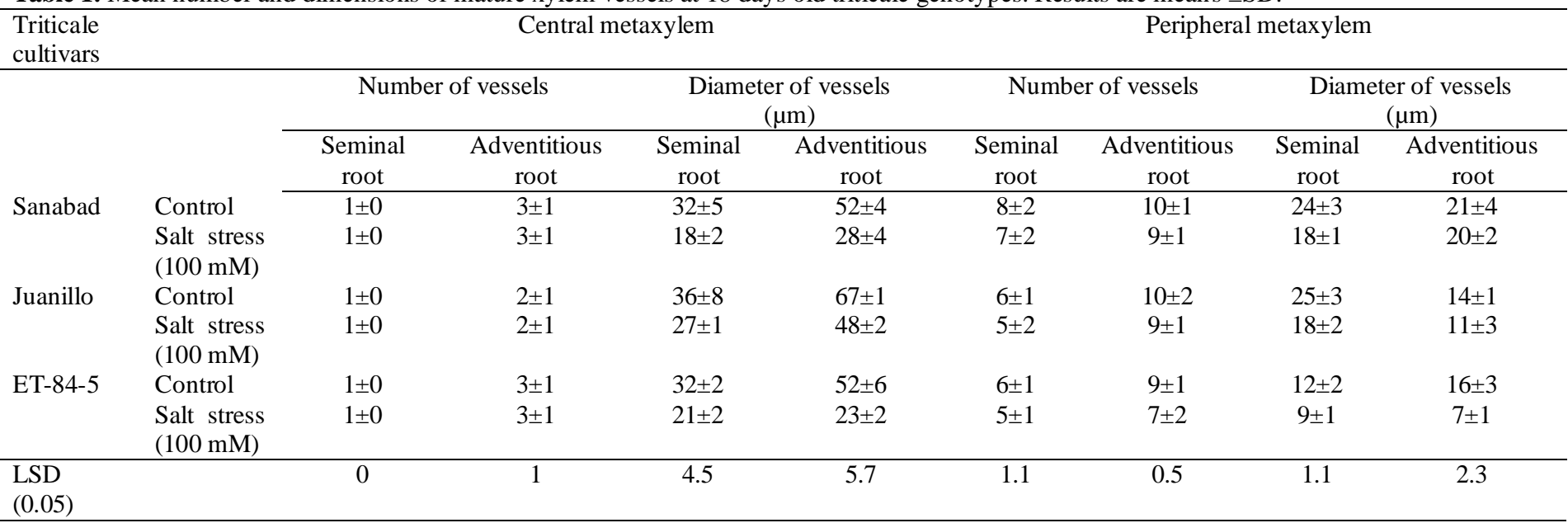

(a)

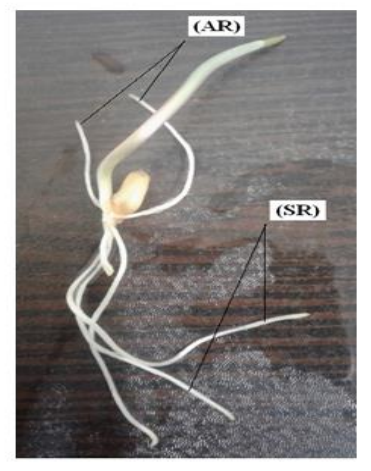

(b)

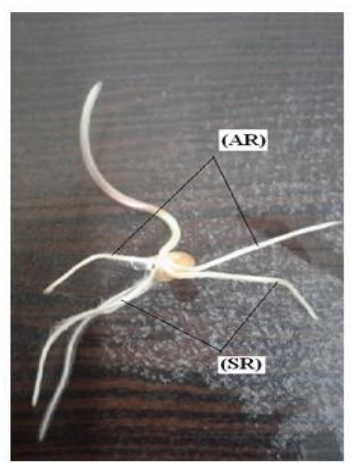

Fig 1. Root development in triticale (Sanabad genotype) under $0 \mathrm{mM} \mathrm{NaCl}(\mathrm{a})$ and $100 \mathrm{mM} \mathrm{NaCl(b).} \mathrm{SR:} \mathrm{seminal} \mathrm{root,} \mathrm{AR:}$ adventitious root.

Table 2. The lignified thickness of cell walls in central and peripheral metaxylem vessels of the seminal and adventitious roots at 18 days old of triticale genotypes.

\begin{tabular}{|c|c|c|c|c|c|c|c|c|}
\hline \multirow{4}{*}{$\begin{array}{l}\text { Triticale } \\
\text { genotypes }\end{array}$} & \multicolumn{4}{|c|}{ Lignified thickness } & \multicolumn{4}{|c|}{ of cell walls $(\mu \mathrm{m})$} \\
\hline & \multicolumn{4}{|c|}{ Seminal root } & \multicolumn{4}{|c|}{ Adventitious root } \\
\hline & \multicolumn{2}{|c|}{ Central metaxylem } & \multicolumn{2}{|c|}{ Peripheral metaxylem } & \multicolumn{2}{|c|}{ Central metaxylem } & \multicolumn{2}{|c|}{ Peripheral metaxylem } \\
\hline & Control & $\begin{array}{l}\text { Salt stress } \\
(100 \mathrm{mM})\end{array}$ & Control & $\begin{array}{c}\text { Salt stress } \\
(100 \mathrm{mM})\end{array}$ & Control & $\begin{array}{l}\text { Salt stress } \\
(100 \mathrm{mM})\end{array}$ & Control & Salt stress $(100 \mathrm{mM})$ \\
\hline Sanabad & 1.82 & 2.31 & 2.13 & 2.93 & 0.97 & 1.29 & 2.12 & 2.91 \\
\hline Juanillo & 0.73 & 0.87 & 0.78 & 1.04 & 0.32 & 0.46 & 1.36 & 1.76 \\
\hline ET-84-5 & 1.69 & 2.30 & 2.01 & 2.68 & 0.88 & 1.36 & 2.11 & 2.83 \\
\hline $\operatorname{LSD}(0.05)$ & 0.22 & 0.18 & 0.54 & 0.43 & 0.39 & 0.27 & 0.65 & 0.31 \\
\hline
\end{tabular}

Table 3. Root surface area, and hydraulic conductivity of seminal and adventitious roots of grown triticale genotypes under control (a) and salt stress (b) conditions at 18 days old plant.

\begin{tabular}{|c|c|c|c|c|c|c|c|c|}
\hline \multirow[t]{3}{*}{ Triticale genotypes } & \multicolumn{4}{|c|}{ Seminal root } & \multicolumn{4}{|c|}{ Adventitious root } \\
\hline & \multicolumn{2}{|c|}{$\begin{array}{l}\text { Root surface area } \\
\qquad\left[\left(\mathrm{m}^{2}\right) \times 10^{-3}\right]\end{array}$} & \multicolumn{2}{|c|}{$\begin{array}{c}\text { Hydraulic } \\
\text { conductivity } \\
{\left[(\mathrm{m} / \mathrm{s} / \mathrm{MPa}) \times 10^{-9}\right]}\end{array}$} & \multicolumn{2}{|c|}{$\begin{array}{l}\text { Root surface area } \\
\qquad\left[\left(\mathrm{m}^{2}\right) \times 10^{-3}\right]\end{array}$} & \multicolumn{2}{|c|}{$\begin{array}{l}\text { Hydraulic conductivity } \\
{\left[(\mathrm{m} / \mathrm{s} / \mathrm{MPa}) \times 10^{-10}\right]}\end{array}$} \\
\hline & Control & $\begin{array}{l}\text { Salt stress } \\
(100 \mathrm{mM})\end{array}$ & Control & $\begin{array}{l}\text { Salt stress } \\
(100 \mathrm{mM})\end{array}$ & Control & $\begin{array}{l}\text { Salt stress } \\
(100 \mathrm{mM})\end{array}$ & Control & $\begin{array}{l}\text { Salt stress } \\
(100 \mathrm{mM})\end{array}$ \\
\hline Sanabad & 1.39 & 1.04 & 5.80 & 3.08 & 0.73 & 0.33 & 2.19 & 1.41 \\
\hline Juanillo & 1.92 & 1.67 & 6.95 & 5.32 & 0.81 & 0.59 & 2.64 & 2.33 \\
\hline ET-84-5 & 2.66 & 1.32 & 5.13 & 3.01 & 0.70 & 0.31 & 2.62 & 1.52 \\
\hline LSD (0.05) & 0.36 & 0.23 & 0.63 & 0.17 & 0.28 & 0.18 & 0.66 & 0.47 \\
\hline
\end{tabular}




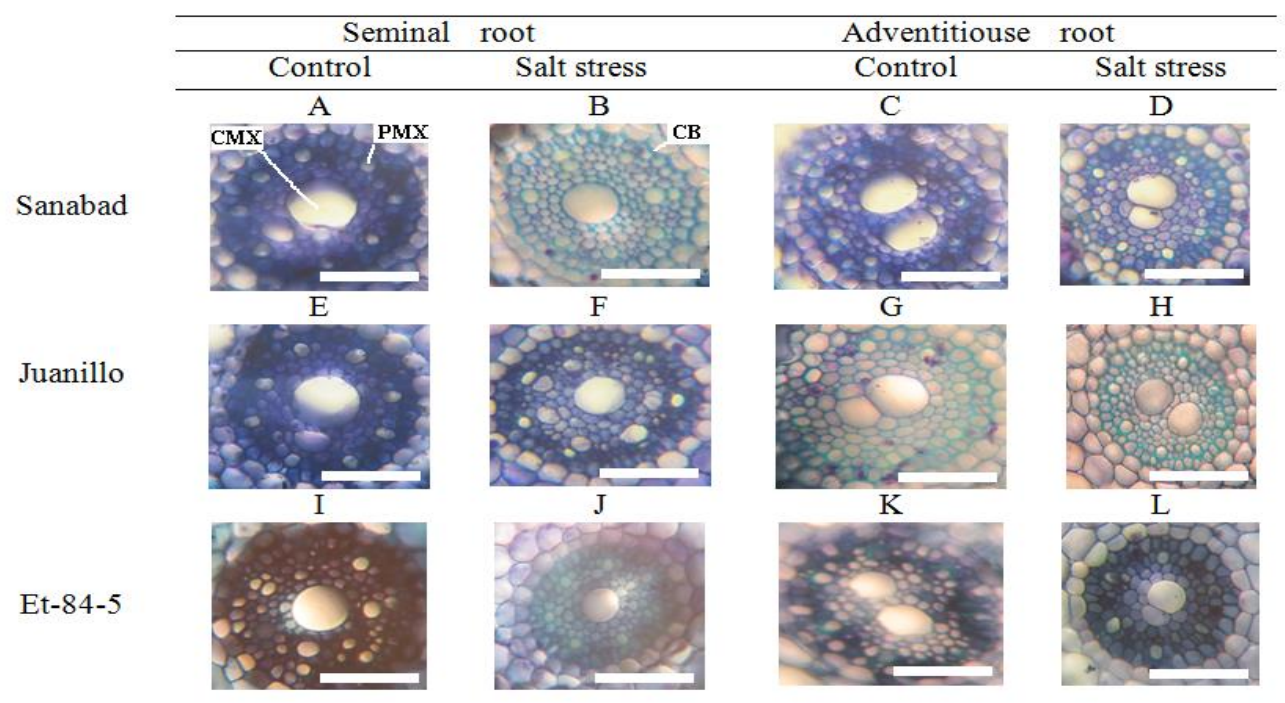

Fig 2. Anatomic structure of xylem in the seminal and adventitious roots of three triticale genotypes including Sanabad (A-D), Juanillo (E-H), and ET-84-5 (I-L) of the 18 days old plants. Hand cross-sections of seminal roots taken at 5-10 mm from seminal and adventitious root tip and stained with berberinehemisulfate and counterstained with toluidine blue and viewed under fluorescence light (390-420 nm) to visualize casparian bands and xylem development. CMX: central metaxylem; PMX: peripheral metaxylem, CB: Casparian bands. Scale bar is $50 \mu \mathrm{m}$.

from 3 to 6 leaf stage, the hydraulic conductivity was $15 \times 10^{-}$ 9 to $36 \times 10^{-9} \mathrm{~m} \mathrm{~s}^{-1} \mathrm{MPa}^{-1}$ and increased with increasing chromosome ploidy during evolution. Gallardo et al. (1996) showed that in wheat (cv. Kulin), the hydraulic conductivity of the seminal roots ranged from 12.3 to $15.2 \times 10^{-8} \mathrm{~m} \mathrm{~s}^{-1}$ $\mathrm{MPa}^{-1}$ at the early growth stages. Fricke et al. (2014) declared that salt stress caused a general reduction $(40-80 \%)$ in hydraulic conductivity of wheat roots, irrespective of whether individual seminal and adventitious roots, entire root systems or intact, transpiring plants were analyzed. Reductions of similar magnitude have been reported for hydraulic conductivity of individual roots and root systems of maize (Azaizeh et al., 1992), barley (Katsuhara and Shibasaka, 2007) and Arabidopsis thaliana L. (Martinez Ballesta et al., 2003) plants after longer-term exposure to salinity. Also, a decrease in wheat root hydraulic conductivity has been reported by Ktitorova et al. (2002) after 1 day of exposure to salt, whereby hydraulic conductivity was derived from the fast kinetics of the changes in root diameter following sudden changes in root medium osmolality.

At normal conditions, no significant difference was observed among the surface area of adventitious roots of triticale genotypes; however, surface area in ET-84-5 and Sanabad significantly decreased under salt stress compared to Juanillo, (Table 3).With respect to root surface area of seminal and adventitious roots, Juanillo with $2.33 \times 10^{-10} \mathrm{~m} \mathrm{~s}^{-1}$ $\mathrm{MPa}^{-1}$ had the highest hydraulic conductivity under salt stress, respectively. Many researches on wheat and barley showed changes in the root hydraulic conductivity might be related to the difference in root surface area, the amount of lignified zone, osmotic driving force and distribution of the seminal and adventitious roots, temperature and nutrients concentration of the medium (Knipfer and Fricke, 2010a; Knipfer and Fricke, 2010b; Fricke et al., 2014). In the present study, under salt stress, the hydraulic conductivities of the seminal and the adventitious roots of Juanillo were significantly greater than those of ET-84-5 and Sanabad genotypes (Table 3).

\section{Growth rate, water loss and root/shoot ratio of triticale genotypes}

Under normal conditions, Sanabad had the maximum growth rate of the third leaf at 17 days after germination (DAG) (Fig. 3a). Under salt stress at 17 DAG, Juanillo with $2.11 \mathrm{~mm} \mathrm{~h}^{-1}$ had the highest growth rate (Fig. 3b). Fricke and Peters (2002) declared that triticale genotypes with higher growth rate and better establishment at the early growth stage grow faster and produce greater yield under salt stress conditions. As plant biomass increased from 14 to 18 DAG, water loss enhanced in all cultivars, especially in ET-84-5 and Sanabad under normal condition (Fig. 4a). Also, at 18 DAG, under salt stress, Sanabad and ET-84-5 with 0.25 and 0.22 g plant $^{-1}$ $\mathrm{h}^{-1}$ had the highest water loss rate while Juanillo, under both normal and salt stress conditions, had the lowest water loss (Fig. 4a). Similarly, Fricke et al. (2010) reported that water loss in salinized barley plants remained lower than normal conditions due to stomata closure under salt stress. Likewise, Vysotskaya et al. (2010) reported that salt treatment $(75 \mathrm{mM})$ inhibited water loss in tolerated barley cultivars more than sensitive cultivars.

Generally, salinity affected the root/shoot ratio of ET-84-5 and Sanabad negatively, while in Juanillo cultivars, salt stress increased the root/shoot ratio (Fig. 5). Caird et al. (2007) reported that root/shoot ratio was an important index in predicting water loss, water uptake, and the hydraulic conductivity in the $\mathrm{C}_{3}$ plants. Under salt stress, the lower root/shoot ratio in ET-84-5 and Sanabad (Fig. 5) might be related to higher water loss [Fig. 4b, (Steudle, 2000)] and more lignified cell walls in the seminal and adventitious roots (Fig. 2) at the third leaf stage.

\section{Materials and Methods}

\section{Plant materials}

To consider the effect of salt stress on root anatomy and hydraulic conductivity of three triticale genotypes including Sanabad, Juanillo, and ET-84-5 an experiment was conducted 
at Agricultural College and Natural Resources of Darab, Shiraz University in 2012, hydroponically. All seeds of genotypes were prepared from Research Center of Fars Province, Iran. Twenty plants from each triticale cultivar including Sanabad, Juanillo, and ET-84-5 at two concentrations of $\mathrm{NaCl}(0$ and $100 \mathrm{mM} \mathrm{NaCl})$ were compared in a completely randomized design with three replications.

\section{Plant growth in Hoagland nutrient solution}

The seeds were first bubbled in distilled water for one day and then put in $\mathrm{CaSO}_{4}$ solution in a 10-liter beaker and were aerated for 4 days. When seedlings had a root length of 25$30 \mathrm{~mm}$, they were transferred to a hydroponic system, containing a modified half-strength Hoagland nutrient solution $\left[\mathrm{KH}_{2} \mathrm{PO}_{4}(1.5 \mathrm{mM}), \mathrm{KNO}_{3}(2.0 \mathrm{mM}), \mathrm{CaCl}_{2}(1.0\right.$ $\mathrm{mM}), \mathrm{MgSO}_{4}(1.0 \mathrm{mM}), \mathrm{FeNa}(18.0 \mu \mathrm{M}), \mathrm{H}_{3} \mathrm{BO}_{3}(8.1 \mu \mathrm{M})$, $\left.\mathrm{MnCl}_{2}(1.5 \mu \mathrm{M})\right]$ (Fricke et al., 1997). Four plants were kept in each 1-liter glass beaker and the nutrient solution was ventilated by a gas exchange pump at a flow rate of $400 \mathrm{~mL}$ $\mathrm{min}^{-1}$ in growth chamber. Plants were kept at a day/night photoperiod of $16 / 8$ hours and temperature of $20 / 15^{\circ} \mathrm{C}$. Relative humidity was $70 \%$ and photosynthetic active radiation at the level of the developing leaf 3 was 350-450 $\mu \mathrm{mol} \mathrm{m} \mathrm{m}^{-2} \mathrm{~s}^{-1}$. Plants were sampled at early growth stages (ZGS13; Zadoks et al., 1974) before the root system became complex and difficult to handle (tangled lateral roots), which makes likely damages to roots and causes electrolyte leakage. Then, Root anatomy, root surface area, hydraulic conductivity, growth rate, and water loss in 14 to 18 days old plants were measured according to the following procedures:

\section{Root anatomical structures and surface area}

Root anatomical structures were considered on free-hand cross-sections that were made from $5-10 \mathrm{~mm}$ root tips (Steudle, 2000). For detection of central and peripheral metaxylem, casparian bands and lignified cell walls (bright signal in Fig.2), sections were stained for 30 minutes with $0.1 \%$ berberine hemisulfate and counterstained for 1-3 minutes with $0.5 \%$ toluidine blue (Hachez et al., 2006). Then, sections were observed with a Canon microscope (HL 1891, Japan) under fluorescence light by a UV/violet filter with an excitation wavelength of 390-420 nm and images were captured with a digital camera.

Surface area of the roots was determined by measuring the length and the radius of the main axis of seminal and adventitious roots and the number, length, and diameter of the lateral roots of the 18-day-old plants. Surface area was calculated by treating roots as cylinders (Knipfer and Fricke, 2010b).

Total root area $\left(\mathrm{A}_{\mathrm{r}}\right)$ was calculated as:

$\mathrm{A}_{\mathrm{r}}=2 \pi \mathrm{r}_{1} \mathrm{~L}_{1}+2 \pi \mathrm{r}_{2} \mathrm{~L}_{2}+2 \pi \mathrm{r}_{3} \mathrm{~L}_{3}+2 \pi \mathrm{r}_{4} \mathrm{~L}_{4}$

Where, $\mathrm{r}_{1}=$ Main root radius $\approx 250 \mu \mathrm{m} ; \mathrm{L}_{1}=\approx$ Main root length; $\mathrm{r}_{2}=$ Lateral $\operatorname{root}(\mathrm{I})$ radius $\approx$

$125 \mu \mathrm{m} ; \mathrm{L}_{2}=$ Lateral root (I) length; $\mathrm{r}_{3}=$ Lateral root (II) radius $\approx 62.5 \mu \mathrm{m} ; \mathrm{L}_{3}=$ Lateral root (II) length; $\mathrm{r}_{4}=$ Lateral $\operatorname{root}\left(\right.$ III) radius $\approx 31.25 \mu \mathrm{m}, \mathrm{L}_{4}=$ Lateral root (III) length.

\section{Root exudation method for Determination of root hydraulic conductivity}

An individual root was attached with the excised root base to a glass capillary (diameter $0.5 \mathrm{~mm}$ ). The rise of the xylem sap in the capillary was measured in 5 minutes intervals for one hour. Exudate volume $\left(\mathrm{V}_{\mathrm{e}}\right)$ was used to determine the hydraulic properties of the roots. $\mathrm{V}_{\mathrm{e}}$ and the hydraulic conductivity of the root $\left(\mathrm{L}_{\mathrm{pr}}\right)$ were determined as below (Knipfer and Fricke, 2010b):

$\mathrm{L}_{\mathrm{pr}}=\mathrm{V}_{\mathrm{e}} \cdot(1 / \Delta \mathrm{t}) \cdot(1 / \Delta \mathrm{p}) \cdot\left(1 / \mathrm{A}_{\mathrm{r}}\right)$

$\mathrm{V}_{\mathrm{e}}=\pi \mathrm{r}^{2} \mathrm{~h}$

$\Delta \mathrm{p}=\mathrm{P}_{\mathrm{e}}-\mathrm{P}_{\mathrm{m}}$

Where, $\mathrm{r}=$ Radial of glass capillary $(250 \mu \mathrm{m}) ; \mathrm{h}=$ Height of the root exudates in glass capillary, $\mathrm{t}=$ Time of going up the root exudates in the glass capillary, $\mathrm{P}_{\mathrm{e}}=$ osmotic potential of the root exudates, and $\mathrm{Pm}=$ osmotic potential of the medium. The osmolality of root exudates $\left(\mathrm{P}_{\mathrm{e}}\right)$ and medium $\left(\mathrm{P}_{\mathrm{m}}\right)$ was determined by Picolitre Osmometry (Model P302, UK). Samples were either analyzed or stored under a liquid paraffin layer (to minimize evaporation) in $0.2-\mathrm{ml}$ centrifuge tubes at $4^{\circ} \mathrm{C}$ for up to 3 days (Fricke and Peters, 2002)

\section{Growth rate and water loss measurement}

Growth rate of third leaf was measured with a ruler from the base of leaf every 12 hour and averaged to exclude possible temporal effects, daily (Fricke and Peters, 2002; Fricke et al., 2010). The water loss of entire plants was determined gravimetrically in the growth chamber. Single barley plants were placed in a measuring cylinder, which was filled with Hoagland nutrient solution and placed on a balance and water loss was measured daily compared to control (i.e. cylinder with Hoagland nutrient solution without plant) in 14 to 18 days old seedlings (Steudle and Peterson, 1998). Finally, dry matter of roots and shoots of the 18 days old seedlings, were measured after being dried in $75^{\circ} \mathrm{C}$ for 72 hours. Analysis of the variance was performed using SAS software and the mean comparisons were performed using LSD test at 5\% probability level.

\section{Conclusion}

It could be concluded that at the early growth stages of the triticale genotypes (3rd leaf stage), the root structures of the Juanillo appeared to be more efficient for water uptake via seminal and adventitious roots. This might be attributed to less lignified cell wall of peripheral and central metaxylem zones of the roots compared to the Sanabad and ET-84-5. Further research to compare the root anatomy and hudrulic conductivity of triticale salt tolerance genotypes may shed more light on this subject.

\section{Acknowledgments}

Author would like to thank Shiraz University for providing the financial support for this research project.

\section{References}

Azaizeh H, Gunse B, Steudle E (1992) Effects of $\mathrm{NaCl}$ and $\mathrm{CaCl} 2$ on water transport across root cells of maize (Zea mays L.) seedlings. Plant Physiol. 99: 886-894.

Bijanzadeh E, Kazemeini SA (2014) Tissue architecture changes of expanding barley (Hordeum vulgare L.) leaf under salt stress. Aus J Crop Sci. 8:1373-1379.

Blum A (2014) The abiotic stress response and adaptation of triticale-A review. Cereal Res Comm. 42: 359-375.

Bramley H, Turner NC, Turner DW, Tyerman SD (2009) Roles of morphology, anatomy, and aquaporins in determining contrasting hydraulic behavior of roots. Plant Physiol. 150: 348-364. 
Caird MA, Richards JH, Donovan LA (2007) Night time stomatal conductance and transpiration in $\mathrm{C}_{3}$ and $\mathrm{C}_{4}$ plants. Plant Physiol. 143: 4-10.

Cavusoglu K, Kilic S, Kabar K (2007) Some morphological and anatomical observations during alleviation of salinity $(\mathrm{NaCl})$ stress on seed germination and seedling growth of barley by polyamines. Acta Physiol Plant. 29: 551-557.

Flowers TJ (2004). Improving crop salt tolerance. J Exp Bot. 55: 307-319.

Fricke W, Peters WS (2002) The biophysics of leaf growth in salt-stressed barley. A study at the cell level. Plant Physiol. 129: $374-388$

Fricke W, Akhiyarova G, Wei W, Alexandersson E (2010) The Short term growth response to salt of developing barley leaf. J Exp Bot. 57: 1079-1095.

Fricke W, Bijanzadeh E, Emam Y, Knipfer T (2014). Root hydraulics in salt-stressed wheat. Fun Plant Bio. 41: 366378.

Fricke W, McDonald, AJS, Mattson Djos L (1997) Why do leaves and leaf cells of $\mathrm{N}$-limited barley elongate at reduced rates? Planta. 202: 522-530.

Gallardo M, Eastham J, Gregory PJ, Turner NC (1996) A comparison of plant hydraulic conductances in wheat and lupins. J Exp Bot. 47: 233-239.

Hachez C, Moshelion M, Zelazny E, Cavez D, Chaumont F (2006) Localization and quantification of plasma membrane aquaporin expression in maize primary roots: A clue to understand their role as cellular plumbers. Plant Mol Bio. 62: 305-323.

$\mathrm{Hu}$ Y, Fromm J, Schmidhalter U (2005) Effect of salinity on tissue architecture in expanding wheat leaves. Planta. 220: 838-848.

Hwang YH, Chen SC (1995) Anatomical responses in Kandelia candel (L.) druce seedlings growing in the presence of different concentrations of $\mathrm{NaCl}$. Bot Bull Acad Sinica. 36: 181-188.

Javot H, Maurel C (2002) The role of aquaporins in root water uptake. Ann Bot. 90: 301-313.

Karray-Bouraoui N, Zid E, Grignon C (2001) K/Na selectivity for secretion into the xylem in triticale (XTriticosecale Wittmack). Dev Plant Soil Sci. 92:420-421.

Katsuhara M, Shibasaka M (2007) Barley root hydraulic conductivity and aquaporin expression in relation to salt tolerance. Soil Sci Plant Nut. 53: 466- 470.

Knipfer T, Fricke, W (2010a) Root pressure and a solute reflection coefficient close to unity exclude a purely apoplastic pathway of radial water transport in barley (Hordeum vulgare L.). New Phytol. 187: 159-170.

Knipfer T, Fricke W (2010b) Water uptake by seminal and adventitious roots in relation to whole-plant water flow in barley (Hordeum vulgare L.). J Exp Bot. 61, 1-17.

Knipfer T, Steudle E (2008) Root hydraulic conductivity measured by pressure clamp is substantially affected by internal unstirred layers. J Exp Bot. 59: 2071-2084.
Kramer PJ, Boyer M (1995) Water relations of plants and soils. Academic Press, Orlando, 331 pp.

Ktitorova IN, Skobeleva OV, Sharova EI, Ermakov EI (2002) Hydrogen peroxide appears to mediate a decrease in hydraulic conductivity in wheat roots under salt stress. Rus J Plant Physiol. 49: 369-380.

Martinez Ballesta, MC, Aparicio F, Pallas V, Martinez V, Carvajal M (2003) Influence of saline stress on root hydraulic conductance and PIP expression in Arabidopsis. Plant Physiol. 160: 689-697.

Maurel C, Simonneau T, Sutka M (2010) The significance of roots as hydraulic rheostats. J Exp Bot. 61: 3191-3198.

Munns R (2005) Genes and salt tolerance: bringing them together. New Phytol. 167: 645-663.

Passioura JB, Munns R (1984) Hydraulic resistance of plants. II. Effects of rooting medium, and time of day, in barley and lupin. Aust J Plant Physiol. 11: 341-350.

Peterson CA, Murran M, Steudle E (1993) Location of major barriers to water and ion movement in young roots of maize (Zea mays L.). Planta. 190P: 127-136.

Rakeih N, Kayyal H, Larbi A, Habib N (2008) Effects of Nacl on above and below growth of triticale lines (X. Triticosecal Wittmack) and barley cultivar at two phenological stages under controlled conditions. Bio Sci Ser. 3: 217-234

Salehi M, Arzani A (2011) Effect of salinity stress on morpho-physiological traits of triticale lines. Iranian Crop Sci J. 13: 697-711. (In Persian)

Steudle E (2000) Water uptake by plant roots: An integration of views. Plant Soil. 226: 46-56.

Steudle E, Peterson CA (1998) How does water get through roots? J Exp Botany. 49: 775-788.

Veselov DS, Sharipova GV, Akhiyarova GR, Kudoyarova GR (2009) Fast growth responses of barley and durum wheat plants to $\mathrm{NaCl}$ and PEG treatment: resolving the relative contributions of water deficiency and ion toxicity. Plant Gro Reg. 58:125-129.

Vysotskaya L, Hedley PE, Sharipova G, Veselov DS, Kudoyarova J, Jones HG (2010) Effect of salinity on water relations of barley plants differing in salt stress. AoB Plants. 12: 616-624.

Zadoks JC, Chang TT, Konzak CF (1974) A decimal code for the growth stages of cereals. Weed Res. 14: 415-421.

Zhao CX, Deng XP, Shan L, Steudle E, Zhang S, Ye Q (2005) Changes in root hydraulic conductivity during wheat evolution. Acta Bot Sin. 47: 302-310. 